\title{
Root Initiation in Debladed Petioles from Juvenile and Mature English Ivy in Response to Inhibitors of Ethylene Biosynthesis and Action
}

\author{
Robert L. Geneve ${ }^{1}$ \\ Department of Horticulture and Landscape Architecture, University of Kentucky, Lexington, \\ KY 40546 \\ Wesley P. Hackett ${ }^{2}$ and Bert T. Swanson ${ }^{2}$
Department of Horticultural Science and Landscape Architecture, University of Minnesota, \\ St. Paul, MN 55108 \\ Additional index words. Hedera helix, rooting, NAA, AVG, AOA, STS, NDE
}

\begin{abstract}
Several inhibitors of ethylene biosynthesis and action, as well as an atmospheric ethylene scrubber, were used to investigate the role of ethylene in adventitious root initiation in de-bladed petioles from the juvenile and mature phase of English ivy (Hedera helix L.). Induction of root primordia required NAA regardless of the inhibitor treatment. Difficult-to-root mature petioles have been shown to produce higher amounts of ethylene than easy-to-root juvenile petioles. However, mature petioles failed to root under any combination of NAA and inhibitor treatment, indicating that the continued evolution of ethylene in NAA-treated mature petioles was not responsible for the absence of a rooting response. Root initiation in juvenile petioles was not affected by treatment with the ethylene action inhibitors STS and NDE, nor by removal of atmospheric ethylene with $\mathrm{KMnO}_{4}$. Inhibition of ethylene biosynthesis using AVG or AOA reduced root initiation in juvenile petioles, but this response was not well-correlated to the observed reduction in ethylene evolution. The inhibitory action of AVG could not be reversed by the addition of ethylene gas or ACC, which indicated that AVG could be acting through a mechanism other than the inhibition of ethylene biosynthesis. Chemical names used: 1-naphthalene acetic acid (NAA); 1-aminocyclopropane-1-carboxylic acid (ACC); silver thiosulfate (STS); 2,5-norbornadiene (NDE); aminoethyoxyvinyl-glycine (AVG); aminooxyacetic acid (AOA)
\end{abstract}

Auxin stimulates adventitious root initiation (9) as well as ethylene production (18) in many plant tissues. However, the role of ethylene in root initiation is still unclear. Inhibitors of ethylene biosynthesis or ethylene action have been used as a means of separating the auxin and ethylene effects on root initiation. Robbins et al. (13), using mung bean cuttings, have reported a reduction in root initiation with the application of AVG, a potent inhibitor of ethylene biosynthesis. In a later report, Robbins et al. (14) treated mung bean cuttings in a recirculating solution system with the ethylene action inhibitors STS or NDE. They observed no effect on the mean number of roots per cutting due to a silver pretreatment, but observed a significant decrease in root initiation using NDE. Linkins et al. (11) eliminated rooting in $1 \mathrm{H}$-indoleacetic acid-treated bean petiole explants by scrubbing the atmospheric ethylene from assay vessels using mercuric perchlorate. In contrast, Coleman et al. (4), using cultured tomato leaf disks, observed an enhancement in rooting due to either silver nitrate in the medium or mercuric perchlorate in the vessel. Batten and Mullins (2), however, showed that neither the inhibition of ethylene action with high $\mathrm{CO}_{2}$ nor the hypobaric removal of ethylene had an effect on rooting in etiolated mung bean cuttings.

In a previous study, debladed petioles from juvenile phase leaves of English ivy were shown to respond to auxin by forming adventitious roots, while mature-phase petioles respond to auxin over a wide concentration range by forming callus only (5). Geneve et al. (6) have also shown a significant difference

Received for publication 12 Sept. 1988. The cost of publishing this paper was defrayed in part by the payment of page charges. Under postal regulations, this paper therefore must be hereby marked advertisement solely to indicate this fact.

Assistant Professor.

${ }^{2}$ Professor. in ethylene evolution from petioles of the two forms treated with NAA. Ethylene evolution from NAA-treated juvenile petioles subsided from a maximum level at $48 \mathrm{hr}$ after treatment to near control (no auxin treatment) levels after 10 days. Ethylene evolution in mature petioles was similar to juvenile petioles after $48 \mathrm{hr}$ but continued to increase slowly over the remainder of the 12-day experimental period. The difference in the pattern of ethylene evolution in juvenile and mature petioles during the period of root initiation suggested that root initiation potential may be related to ethylene biosynthesis and action.

The objectives of this study were: 1) to determine the effects of several ethylene inhibitors on adventitious root initiation in debladed petioles of juvenile and mature English ivy, and 2) to assess the possible role of ethylene in the low rooting potential of mature petiole cuttings.

\section{Materials and Methods}

Debladed petioles from mature and juvenile English ivy were assayed for their rooting response in vitro as described previously (5). AOA, AVG, and NDE were applied alone or in combination with $100 \mu \mathrm{M}$ NAA. AOA and AVG were supplied in the sterile culture medium. Concentrations of NDE were obtained in the gas phase by the complete volatilization of a known amount of the liquid phase. The gaseous NDE was injected into sealed 25-ml Erlenmeyer flasks containing five petioles. The atmosphere of each flask was vented every $24 \mathrm{hr}$ for $15 \mathrm{~min}$ and then reinfected with the appropriate concentration of NDE. The NDE treatment was 12 days long. NAA, AVG, and AOA were present in the medium for 18 days.

Ethylene evolution from AVG-treated petioles was measured in each sealed flask every $24 \mathrm{hr}$ using a Hewlett Packard 5880A gas chromatography (6). The flasks were vented for 15 min after each sampling period and then resealed. Ethylene levels were 
expressed as nanoliters produced during $24 \mathrm{hr}$, based on initial fresh weight.

The specificity of AVG action on ethylene evolution in juvenile petioles was tested by adding $100 \mu \mathrm{M}$ ACC or $10 \mu \mathrm{l}$ of ethylene/liter to petioles treated with $100 \mu \mathrm{M} \mathrm{NAA}+100 \mu \mathrm{M}$ AVG. Ethylene was injected into Erlenmeyer flasks fitted with rubber serum stoppers. Each flask was vented at the end of each 24-hr period, resealed, and reinfected with the appropriate concentration of ethylene for a total of 12 days. The ethylene produced by juvenile petioles treated with $100 \mu \mathrm{M}$ NAA +100 $\mu \mathrm{M} \mathrm{AVG}+100 \mu \mathrm{M}$ ACC in sealed flasks was measured using gas chromatography as described above.

Juvenile and mature petioles were pretreated with $500 \mu \mathrm{M}$ STS (distilled water was used as a control) by placing the base of each petiole of intact individual leaves in $\approx 1 \mathrm{ml}$ of the STS solution. The petioles were pretreated for $5 \mathrm{hr}$ under conditions to ensure transpiration uptake. The lamina was detached from the petiole and then the latter was assayed for rooting, as described previously (5).

To remove endogenously evolved ethylene from the atmosphere surrounding the petioles during the rooting assay, Erlenmeyer flasks containing mature or juvenile petioles were sealed in 240-ml Mason jars fitted with a serum stopper in the lid. Each Mason jar contained a bed of $30 \mathrm{ml}$ of perlite saturated with $\mathrm{KMnO}_{4}$, as described by Saltveit (13), or perlite alone as a control. Gas samples were taken through the serum cap fitted in the Mason jar lid.

The statistical design for all experiments was a nested classification. The values presented for the mean number of roots per cuttings were from representative experiments and were the means for five petioles in each of two replicated flasks.

\section{Results}

Treatment with several concentrations of AOA, AVG or NDE in the absence of NAA did not induce rooting in juvenile and mature petioles (data not presented). Mature petioles did not initiate roots when treated with $100 \mu \mathrm{M}$ NAA plus several concentrations of AOA, AVG (data not presented), or NDE. No reduction or enhancement of root initiation for NAA-treated juvenile or mature petioles was observed at the tested concentrations ( 0 to $\left.6000 \mathrm{ml} \cdot \mathrm{liter}^{-1}\right)$ of NDE, all being in the range of 7.7 to 8.5 roots per cutting. NAA-treated juvenile petioles showed no reduction in the number of roots per cutting when treated with $1 \mu \mathrm{M}$ AOA or AVG, but, at $100 \mu \mathrm{M}$ AOA, root number was reduced from 7.2 to 4.3 roots per cutting (Table 1). Rooting of NAA-treated juvenile petioles was dramatically reduced to less than one root per cutting when treated with 100 $\mu$ M AVG (Table 1).

AVG was an effective inhibitor of ethylene evolution in petioles treated with $100 \mu \mathrm{M}$ NAA (Fig. 1). AVG at 10 and 100 $\mu \mathrm{M}$ reduced the ethylene concentration of $100 \mu \mathrm{M}$ NAA-treated petioles to the levels of the untreated controls. AVG at $1 \mu \mathrm{M}$ reduced the ethylene concentration to a level between the NAAtreated and control petioles.

Mature petioles failed to initiate roots in response to $100 \mu \mathrm{M}$ NAA with or without the addition of $100 \mu \mathrm{M} A V G$ at various times after initiation of culture (Table 2). NAA-treated juvenile petioles were inhibited from initiating roots when $100 \mu \mathrm{M} A V G$ was supplied at day 1 . Inhibition of rooting was gradually reduced as the application of AVG was delayed for 3, 6, or 9 days. Petioles with AVG supplied at day 9 had the same number of roots per cutting as petioles treated with NAA alone (Table 2).
Table 1. Rooting response of juvenile Hedera helix petioles treated with $100 \mu \mathrm{M}$ NAA to inhibitors of ethylene biosynthesis. ${ }^{2}$

\begin{tabular}{ccc}
\hline & \multicolumn{2}{c}{ Inhibitor } \\
\cline { 2 - 3 } $\begin{array}{c}\text { Inhibitor } \\
\text { concn }(\mu \mathrm{M})\end{array}$ & \multicolumn{2}{c}{ No. roots per cutting } \\
\cline { 2 - 3 } 0 & 9.0 & 7.2 \\
1 & 8.9 & 7.4 \\
10 & 7.5 & 5.2 \\
100 & 0.4 & 4.3 \\
Trend analysis & & F value \\
Linear & $86.6^{* *}$ & $20.4^{* *}$ \\
Quadratic & $28.7^{* *}$ & $2.6^{\mathrm{NS}}$ \\
$r^{2}$ & 0.76 & 0.18 \\
\hline
\end{tabular}

${ }^{z}$ Mature petioles failed to root under any of the experimental treatments presented here. Juvenile petioles that were not treated with NAA did not root, regardless of the inhibitor treatment.

Ns, "Nonsignificant at $P=0.05$ or significant at $P=0.01$, respectively.

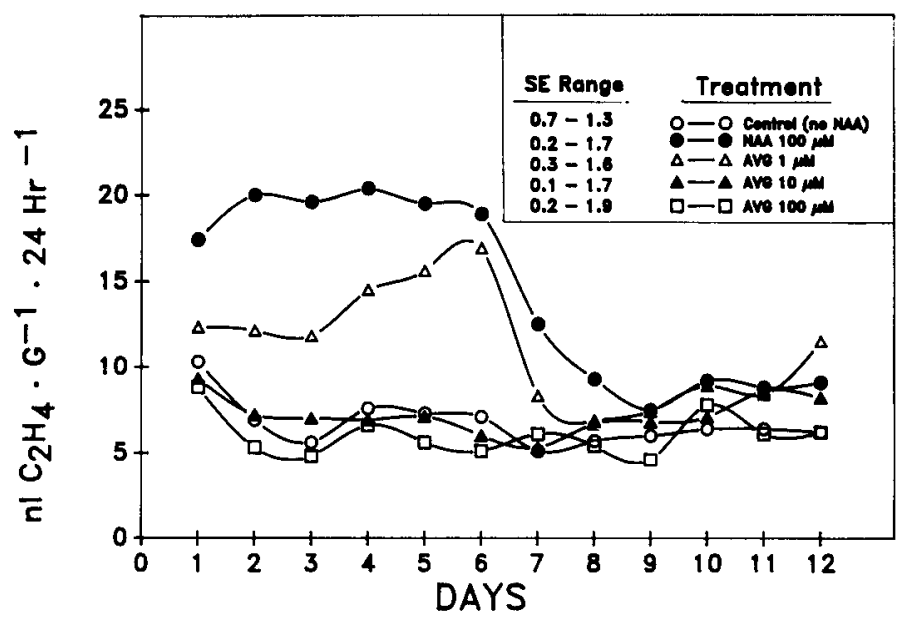

Fig. 1. Time course for ethylene evolution in juvenile petioles treated with $100 \mu \mathrm{M}$ NAA and various concentrations of AVG. Standard error (SE) range indicates the minimum and maximum SEs for the points in a treatment.

Table 2. Rooting response of juvenile petioles treated with $100 \mu \mathrm{M}$ NAA in combination with $100 \mu \mathrm{M}$ AVG supplied at various times after initiation of culture. ${ }^{z}$

\begin{tabular}{cc}
\hline $\begin{array}{c}\text { Application } \\
\text { time (day) }\end{array}$ & Roots per cutting \\
\hline Control (NAA alone) & 9.6 \\
0 & $00^{* *}$ \\
3 & $2.3^{* *}$ \\
6 & $7.1^{\mathrm{NS}}$ \\
9 & $9.3^{\mathrm{Ns}}$ \\
\hline
\end{tabular}

${ }^{z}$ Mature petioles failed to root under any treatment combination. yTreatment means compared to NAA alone using Dunnett's test. NS," Nonsignificant at $P=0.05$ or significant at $P=0.01$, respectively.

Addition of $10 \mu \mathrm{l}$ ethylene/liter or $100 \mu \mathrm{M}$ ACC to NAA + AVG-treated juvenile petioles at day 0 failed to overcome the inhibition of rooting caused by $100 \mu \mathrm{M} \mathrm{AVG}$ (Table 3). Juvenile petioles treated with $\mathrm{NAA}+\mathrm{AVG}+\mathrm{ACC}$ were able to me- 
Table 3. Rooting response of juvenile Hedera helix petioles treated with $100 \mu \mathrm{M}$ NAA to combinations of AVG + ethylene gas or ACC.

\begin{tabular}{lc}
\hline \hline \multicolumn{1}{c}{ Treatment } & $\begin{array}{c}\text { Roots per } \\
\text { cutting }\end{array}$ \\
\hline Control (NAA alone) & $9.6 \mathrm{a}^{\mathrm{y}}$ \\
AVG $(100 \mu \mathrm{M})$ & $0.5 \mathrm{c}$ \\
Ethylene $\left(10 \mu \mathrm{l} \cdot\right.$ liter $\left.^{-1}\right)$ & $5.4 \mathrm{~b}$ \\
ACC $(100 \mu \mathrm{M})$ & $5.7 \mathrm{~b}$ \\
AVG $(100 \mu \mathrm{M})+$ ethylene $\left(10 \mu \mathrm{l} \cdot\right.$ liter $\left.^{-1}\right)$ & $0.0 \mathrm{c}$ \\
AVG $(100 \mu \mathrm{M})+$ ACC $(100 \mu \mathrm{M})$ & $0.6 \mathrm{c}$ \\
\hline
\end{tabular}

${ }^{y}$ Means followed by the same letter were not significantly different at $P=0.05$, as indicated by LSD.

tabolize ACC, as indicated by ethylene evolution (data not presented).

Juvenile or mature petioles pretreated with STS but not treated with NAA did not initiate roots (data not presented). Mature petioles treated with NAA alone or in combination with STS did not initiate roots (data not presented). STS pretreatment had no effect on the number of roots per cutting in NAA-treated juvenile petioles ( 9.2 roots for STS pretreated and 8.2 roots per cutting for non-pretreated). However, pretreatment with silver reduced the characteristic loss of chlorophyll observed in NAAtreated petioles, indicating uptake and action of the silver thiosulphate.

Removal of ethylene from the flask atmosphere with $\mathrm{KMnO}_{4}$ did not affect the number of roots per cutting in NAA-treated juvenile petioles. NAA-treated juvenile petioles placed in $\mathrm{KMnO}_{4}-$ saturated jars produced 5.9 roots per cutting, compared to 6.4 roots for petioles in control jars. Both of these treatments caused a reduction in the number of roots compared to the NAA-treated controls not placed in jars (Table 1). NAA-treated mature petioles failed to initiate roots with or without the scrubbing of ethylene with $\mathrm{KMnO}_{4}$. Ethylene was not detected in the atmosphere of $\mathrm{KMnO}_{4}$-treated jars, while measurable ethylene was detected in the control jars.

\section{Discussion}

Cuttings from the mature phase of English ivy have been demonstrated to be difficult to root $(5,7,8)$. In this study, the possibility that high ethylene production might be involved in the inability of the mature phase to initiate roots was tested using inhibitors of ethylene biosynthesis and action. Mature petioles failed to root regardless of the material used to inhibit ethylene synthesis or action (Tables 1 and 2). Therefore, the failure of mature petioles to initiate roots does not appear to be due to endogenously produced ethylene.

Earlier research indicated that ethylene does not substitute for auxin in stimulating root initiation in juvenile petioles (6). These data did not, however, eliminate the possibility that auxin-stimulated production of ethylene had a physiological role in root initiation. The results presented here showed that several inhibitors of ethylene action had no effect on rooting, while inhibitors of ethylene biosynthesis (AVG and AOA) had an inhibitory effect on root initiation (Table 1). These apparently conflicting results leave the role of ethylene in adventitious root initiation for juvenile petioles still in question. However, the following discussion may provide an explanation for these conflicting results.

AVG and AOA are inhibitors of pyridoxal phosphate-requiring enzymes and thereby inhibit the biosynthesis of ethylene by blocking the conversion of S-adenosylmethionine to ACC (19). In NAA-treated juvenile petioles, AOA and AVG were inhibitory to rooting at 10 and $100 \mu \mathrm{M}$, with $100 \mu \mathrm{M}$ AVG reducing rooting to less than one root per cutting (Table 1). However, the inhibition of root initiation by AVG may not be due entirely to the reduction of ethylene evolution. The reduction in ethylene evolution was nearly identical for petioles treated with 10 and $100 \mu \mathrm{M}$ AVG (Fig. 1), while root initiation was reduced to a much greater extent at 100 than $10 \mu \mathrm{M}$ AVG (Table 1). Thus, the reduction in the number of roots per cutting caused by increasing the AVG concentration 10-fold was not due to decreased ethylene production. This was reinforced by the fact that inhibition of rooting in AVG-treated cuttings could not be overcome by adding back ethylene or ACC to NAA + AVGtreated petioles (Table 3). Petioles treated with NAA + AVG + ACC were, however, able to metabolize ACC to ethylene in an apparent normal manner (data not presented). These results were consistent with expectations, since AVG acts to inhibit the production of ACC and not the synthesis of ethylene from ACC (19) and support the results with AVG-treated mung bean cuttings $(10,12)$. In these reports, ACC was also unable to reverse AVG-inhibited root formation. On the basis of these results, the reduction in rooting by $\mathrm{AVG}$ may be better explained by its effect on pyridoxal phosphate-requiring enzymes that are not related to ethylene biosynthesis but may be important to root initiation.

The results of delaying the application of $100 \mu \mathrm{M} \mathrm{AVG}$ for 3 , 6, or 9 days (Table 2) indicated that the early stages of root initiation (5) were the most sensitive to AVG inhibition. AVG inhibition of rooting was lost when AVG was added 9 days after the start of the assay. The reduction and elimination of AVG inhibition of rooting as a result of delaying AVG treatment could be interpreted as indicating an early requirement for ethylene in root initiation. This conclusion, however, is not substantiated by the failure of ethylene treatment to overcome the AVG inhibition of root initiation (see above). It may be more appropriate to conclude that the critical early inductive stages of rooting were sensitive to inhibition of enzymes requiring pyridoxal phosphate as a cofactor.

Several approaches were used to reduce levels of ethylene or inhibit the action of ethylene in NAA-treated juvenile petioles: 1) competing for the ethylene binding site with $\operatorname{NDE}(14,15)$, 2 ) altering the binding site with silver $(3,18,19)$, and 3) scrubbing the atmosphere with $\mathrm{KMnO}_{4}(1,15)$. The results with NDE indicated no effect on root initiation over the range of concentrations tested. NDE at concentrations similar to those used in this study has been shown to effectively counteract the ethylene effect on abscission of citrus leaves (16) and to delay the senescence of carnation flowers (17). Likewise, no effect on root initiation in juvenile petioles was observed when petioles were pretreated with STS or when petioles were rooted in a flask atmosphere with reduced ethylene levels obtained by scrubbing with $\mathrm{KMnO}_{4}$. These results using inhibitors of ethylene action and reduced ethylene levels indicate no relationship between ethylene action and auxin-stimulated root initiation in juvenile petioles.

Several conclusions can be drawn from the evidence presented in this study: 1) the inability of mature petioles to initiate roots could not be explained as a simple inhibition of root initiation by endogenously produced ethylene; 2 ) ethylene was not required for root initiation in auxin-treated juvenile petioles since the effect on rooting of various ethylene inhibitors was minimal (except for $100 \mu \mathrm{M} A V G) ; 3$ ) endogenous ethylene production 
does not limit the number of roots per cutting, since there was no increase in root initiation after inhibitor treatment as compared to the juvenile petioles treated with NAA alone; and 4) care should be taken in concluding that AVG acts specifically to reduce rooting by inhibiting biosynthesis of ethylene.

\section{Literature Cited}

1. Abeles, F.B. 1973. Ethylene in plant biology. Academic, New York.

2. Batten, D.J. and M.G. Mullins. 1978. Ethylene and adventitious root formation in hypocotyl segments of etiolated mung bean (Vigna radiata) seedlings. Planta 138:193-197.

3. Beyer, E. 1976. Silver ion: a potent antiethylene agent in cucumber and tomato. HortScience 11:195-196.

4. Coleman, W.K., T.J. Huxter, D.M. Reid, and T.A. Thorpe. 1980. Ethylene as an endogenous inhibitor of root regeneration in tomato leaf discs cultured in vitro. Physiol. Plant. 48:519525 .

5. Geneve, R.L., W.P. Hackett, and B.T. Swanson. 1988. Adventitious root initiation in de-bladed petioles from the juvenile and mature phase of English ivy. J. Amer. Soc. Hort. Sci. 113:630635.

6. Geneve, R.L., W.P. Hackett and B.T. Swanson. 1989. Ethylene production in debladed petioles from the juvenile and mature phase of English ivy in relation to adventitious root initiation. J. Amer. Soc. Hort. Sci. 115(1):123-127.

7. Girouard, R.M. 1967. Initiation and development of adventitious roots in stem cuttings of Hedera helix. Anatomical studies of the mature growth phase. Can. J. Bot. 45:1883-1886.

8. Hackett, W .P. 1970. The influence of auxin, catechol and methanolic tissue extracts on root initiation in "aseptically cultured shoot apices of the juvenile and adult forms of Hedera helix. J. Amer. Soc. Hort. Sci. 95:398-402.

9. Hartman, H.T. and D.E. Kester. 1983. Plant propagation: Principles and practices. Prentice-Hall, Englewood Cliffs, N.J.

10. Jusaitis, M. 1986. Rooting response of mung bean cuttings to 1aminocyclopropane -1-carboxylic acid and inhibitors of ethylene biosynthesis. Scientia Hort. 29:77-85.

11. Linkins, A.E., L.N. Lewis, and R.L. Palmer. 1973. Hormonally induced changes in stem and petiole anatomy and cellulase enzyme patterns in Phaseolus vulgaris. Plant Physiol. 52:554-560.

12. Riov, J. and S.F. Yang. 1989. Ethylene and auxin-ethylene interaction in adventitious root formation in mung bean (Vigna radiata) cuttings. J. Plant Growth Regulat. 8:131-141.

13. Robbins, J.A., S.J. Kays, and M.A. Dirr. 1983. Enhanced rooting of wounded mung bean cuttings by wounding and ethephon. J. Amer. Soc. Hort. Sci. 108:325-329.

14. Robbins, J.A., M.S. Reid, J.L. Paul, and T.L. Rest. 1985. The effect of ethylene on adventitious root formation in Mung bean (Vigna radiata) cuttings. J. Plant Growth Regulat 4:147-157.

15. Saltveit, M.E. 1980. An inexpensive chemical scrubber for oxidizing volatile organic contaminants in gases and storage room atmospheres. HortScience 15:759-760.

16. Sisler, E.C., R. Goren, and M. Huberman. 1985. Effect of 2,5norbornadiene on abscission and ethylene production in citrus leaf explants. Physiol. Plant. 63:114-120.

17. Sisler, E.C., M.S. Reid, and D.W. Fujino. 1983. Investigation of the mode of action of ethylene in carnation senescence. Acts Hort. 141:229-234.

18. Yang, S.F. 1980. Regulation of ethylene biosynthesis. HortScience 15:238-243.

19. Yang, S.F. and N.E. Hoffman. 1984. Ethylene biosynthesis and its regulation in higher plants. Annu. Rev. Plant Physiol. 35:155189. 